\title{
Pengembangan M-Kamus Istilah Penelitian dalam Bahasa Arab bagi Mahasiswa Pendidikan Bahasa Arab Universitas Negeri Semarang
}

\author{
Muhammad Hakim Azzikri \\ Universitas Negeri Semarang \\ hakimazzikri@gmail.com
}

\section{Zukhaira}

Universitas Negeri Semarang

zukhaira unnes@yahoo.com

DOI: http://dx.doi.org/10.18326/lisania.v3i2.128-142

\begin{abstract}
The purpose of this research was to develope a special dictionary based on Android mobile applications or m-Dictionary of Research Terms in Arabic. The type of this research was research and development ( $R \& D)$. The data were obtained through non-tests, namely questionnaires for student needs, questionnaires for expert validation tests, and interviews. The conclusion that can be taken from this study is that the students need a special dictionary based on Android mobile applications or M-Dictionary of Research Terms in Arabic which contains research terms in Arabic with the main components in the mdictionary based on needs analysis are the main page, search, bookmark, usage instructions, profile, about M-Dictionary, and suggestions. Based on the results of the application validation test questionnaire, M-Dictionary of Research Terms in Arabic gets a total value of 86.57 which means that application of the m-Dictionary of Research Terms in Arabic is feasible to use.
\end{abstract}

Keywords: e-Dictionary, Research Terms, Android

\begin{abstract}
Abstrak
Penelitian ini bertujuan untuk pengembangan M-Kamus istilah penelitian dalam bahasa arab bagi mahasiswa Pendidikan Bahasa Arab di Universitas Negeri Semarang. Desain penelitian ini adalah research and development. Data pada penelitian ini diperoleh melalui non tes, yaitu angket kebutuhan mahasiswa, angket uji validasi ahli, dokumentasi dan wawancara. Kesimpulan penelitian ini adalah hasil analisis kebutuhan menunjukkan mahasiswa menghendaki M-Kamus Istilah Penelitian dalam Bahasa Arab yang memuat istilah-istilah penelitian dalam bahasa Arab. Dan komponen utama dalam M-Kamus berdasarkan analisis kebutuhan adalah halaman utama, pencarian, penanda, petunjuk penggunaan, profil, tentang M-Kamus, dan saran. Berdasarkan hasil angket uji validasi aplikasi M-Kamus Istilah Penelitian dalam Bahasa Arab mendapatkan nilai total 86,57 yang dapat disimpulkan bahwa aplikasi M-Kamus Istilah Penelitian dalam Bahasa Arab layak untuk digunakan.
\end{abstract}

Kata Kunci: M-Kamus, Istilah Penelitian, Android 


\section{Pendahuluan}

Penelitian merupakan padanan dari kata al-bahts al-'ilmiy yang berarti mencari sesuatu, menyelidiki, dan memeriksa (Sulaiman dalam Ainin, 2010: 8). Menurut istilah, Penelitian adalah proses pengumpulan dan analisis data yang dilakukan secara sistematis dan logis untuk mencapai tujuan tertentu (Sukmadinata 2012 :5). Penelitian adalah cara ilmiah untuk mendapatkan data dengan tujuan dan kegunaan tertentu (Sugiyono 2014: 2). Sedangkan menurut Nazir (dalam Ainin 2010: 9) penelitian adalah suatu metode studi yang dilakukan seseorang melalui penyelidikan yang hati-hati dan sempurna terhadap masalah tersebut. Dengan demikian dapat disimpulkan bahwa penelitian adalah sebuah metode ilmiah untuk mengumpulkan data, kemudian mengolah data, dan menyajikan data tersebut dengan cara yang sistematis untuk mencapai tujuan yang diinginkan dalam penelitian.

Di Indonesia, penelitian erat kaitannya dengan dunia pendidikan, penelitian lebih sering dilakukan dalam jenjang perguruan tinggi. Hal ini sesuai dengan Tri Dharma Perguruan Tinggi, yaitu (1) Pendidikan, (2) Penelitian, dan (3) Pengabdian kepada masyarakat. Tri Dharma Perguruan Tinggi adalah hal-hal dasar yang harus ada saat menjalani aktivitas akademik, dasar dan tanggung jawab tersebut dilakukan secara terus menerus dan dikembangkan secara beriringan. Tanggung jawab Tri Dharma Perguruan Tinggi diberikan kepada seluruh civitas akademika, terutama dosen dan mahasiswa. Dosen sebagai pengajar, pembimbing sekaligus pendamping, sedangkan mahasiswa sebagai anak didik yang menuntut ilmu (www.academicindonesia.com diunduh 5 Januari 2019).

Sebagaimana diamanatkan dalam Peraturan Menteri Riset, Teknologi dan Pendidikan Tinggi Republik Indonesia No.16 Tahun 2015 bahwa dosen adalah pendidik profesional dan ilmuwan dengan tugas utama mentransformasikan, mengembangkan dan menyebar luaskan ilmu pengetahuan, teknologi, dan seni melalui pendidikan, penelitian, dan pengabdian kepada masyarakat.

Bagi mahasiswa di perguruan tinggi, untuk mengamalkan salah satu Tri Dharma Perguruan Tinggi yaitu penelitian, maka setiap mahasiswa wajib melakukan penelitian selama proses belajar di dalam perguruan tinggi. Salah satu penelitian yang bisa dilakukan mahasiswa adalah dengan membuat skripsi. Skripsi adalah karya ilmiah yang disusun atas dasar kajian kepustakaan, penelitian lapangan, dan atau uji laboratorium 
sebagai latihan penulisan ilmiah pada program studi jenjang Strata 1 (S1) dengan bobot 6 SKS (Tim Penyusun, 2018: 1).

Universitas Negeri Semarang (selanjutnya disingkat UNNES) adalah salah satu Perguruan Tinggi yang menggunakan kebijakan skripsi sebagai salah satu mata kuliah yang harus ditempuh atau tugas akhir untuk lulus dan mendapatkan gelar pada jenjang Strata-1 (S1). Sementara itu, berdasarkan kebijakan Program Studi Pendidikan Bahasa Arab (Selanjutnya disingkat PBA) di UNNES, bahwa skripsi mahasiswa PBA di UNNES wajib menggunakan dua bahasa, yaitu bahasa Arab dan bahasa Indonesia.

Berdasarkan hasil angket kebutuhan yang telah peneliti lakukan terhadap mahasiswa PBA di UNNES, bahwa mahasiswa bahasa Arab cukup mengetahui istilahistilah penelitian dalam bahasa Arab. Terbukti dengan penelitian awal yang dilakukan oleh peneliti pada 35 mahasiswa PBA semester enam dan delapan yang dipilih secara acak, mayoritas mahasiswa PBA di UNNES cukup mengetahui istilah-istilah penelitian dalam bahasa Arab, 21 mahasiswa atau 60\% mahasiswa menyatakan cukup mengetahui istilah penelitian dalam bahasa Arab, dan sebanyak 9 mahasiswa atau 25,7\% menyatakan sangat mengetahui. Sisanya, 5 mahasiswa atau 14,3\% mengaku tidak mengetahui. Namun demikian, meskipun banyak yang menyatakan cukup mengetahui, berdasarkan alasan yang diberikan, mereka hanya mengetahui beberapa saja atau hanya sedikit tahu mengenai istilah penelitian dalam bahasa Arab. Hal ini dikarenakan cukup sulitnya menemukan kamus khusus istilah penelitian dalam bahasa Arab, baik berupa kamus cetak maupun kamus elektronik.

Menurut pendapat salah satu mahasiswa PBA di UNNES, pada umumnya mahasiswa bahasa Arab kurang memanfaatkan kamus yang besar dan tebal untuk mencari kosakata atau istilah yang belum diketahui, tetapi mahasiswa bahasa Arab lebih memanfaatkan kamus elektronik, karena dengan kamus elektronik mahasiswa bisa dengan mudah dan cepat untuk mencari kosakata yang belum diketahui. Meskipun ada kelebihan dan kekurangan antara kamus biasa dan kamus elektronik, tetapi mahasiswa lebih cenderung memanfaatkan kamus elektronik.

Ketika mencari istilah penelitian dalam bahasa Arab dengan memanfaatkan kamus elektronik yang sudah ada, mahasiswa bahasa Arab dihadapkan kendala tidak semua istilah penelitian dalam bahasa Arab ada dalam kamus elektronik, maka mahasiswa bahasa Arab harus membuka kamus yang lengkap dengan ukuran besar dan 
tebal. Akan tetapi dengan kamus biasa juga belum bisa membantu mahasiswa bahasa Arab untuk mencari istilah penelitian dalam bahasa Arab dengan cepat dan mudah.

Kamus khusus tentang istilah penelitian bahasa Arab masih sulit didapatkan oleh mahasiswa bahasa Arab di UNNES untuk mencari istilah penelitian dalam bahasa Arab, dengan alasan kamus biasa membutuhkan waktu yang lama, harus mencari asal kata dalam kamus terlebih dahulu, dan kamus online juga sering tidak sesuai, tidak efektif, dan lain sebagainya. Serta dengan berkembangnya teknologi komunikasi, penggunaan smartphone menjadi bagian yang penting dan tidak bisa dilepaskan dari kehidupan sehari-hari. Sehingga penggunaan smartphone saat ini perlu dioptimalkan, termasuk untuk memudahkan para mahasiswa mencari istilah penelitian dalam bahasa Arab.

Belum adanya produk kamus yang berbentuk aplikasi atau M-Kamus khusus yang di dalamnya hanya berisi tentang istilah penelitian dalam bahasa Arab dan berjalan pada perangkat smartphone, menjadikan masalah tersendiri bagi mahasiswa bahasa Arab di UNNES untuk mengetahui dengan mudah dan cepat istilah penelitian dalam bahasa Arab. Kamus adalah buku acuan yang memuat daftar kosakata sedemikian banyak yang disusun secara alfabetis atau sesuai dengan abjad berikut keterangan makna, pemakaian, atau terjemahannya (Izzan, 2015: 190). Menurut Ba'albaqi (dalam Hermawan, 2013: 26) kamus ditinjau dari segi materinya dibagi menjadi dua, yaitu (1) kamus umum (al-mu'jam al-'am) (2) kamus khusus (al-mu'jam al-khash).

Sedangkan menurut Hakim dan Reza (dalam Keswati 2013:21) kamus dibedakan menjadi tiga macam, yaitu : (1) Kamus Buku (mu'jam al-kitab), yaitu kamus yang dibuat untuk memahami makna dari kosakata yang ada dalam sebuah buku, (2) Kamus Digital, yaitu perangkat lunak computer (software) yang memuat program terjemah atau kamus bahasa yang bisa dijalankan melalui media elektronik seperti handphone, computer, PDA, dan perangkat lainnya, (3) kamus On Line, yaitu kamus yang bisa di akses melalui internet.

Android adalah sebuah sistem operasi yang berjalan pada perangkat mobile berbasis linux yang mencakup sistem operasi, middleware, dan aplikasi. Android menyediakan platform terbuka bagi para pengembang untuk menciptakan aplikasi mereka. Awalnya, Android dikembangkan oleh Android, Inc. dengan dukungan finansial dari Google Inc., yang kemudian membeli Android Inc. yang merupakan pendatang baru yang membuat peranti lunak untuk ponsel/smartphone pada tahun 2005. Kemudian 
untuk mengembangkan Android, dibentuklah Open Handset Alliance, konsorium dari 34 perusahaan peranti keras, peranti lunak, dan telekomunikasi, termasuk Google, HTC, Intel, Motorola, Qualcomm, T-Mobile, dan Nvidia. Sistem operasi ini resmi dirilis pada tahun 2007 dan ponsel Android pertama mulai dijual pada bulan Oktober 2008 (Yudhanto \& Wijayanto, 2017: 1).

Pengguna smartphone berbasis sistem Android di Indonesia terbesar dibandingkan sistem operasi smartphone lainnya. Menurut StatCounter (gs.statcounter.com) sistem operasi Android menguasai pasar Indonesia sebesar 92,43\% pada Januari 2019. Sedangkan sistem operasi iOS besutan Apple, Inc. hanya menguasai 5,86\% pasar sistem operasi di Indonesia. Sisanya 1,71\% dikuasai oleh sistem operasi lainnya, seperti Blackberry OS, Symbian OS, dan lainnya.

Mahasiswa juga mendukung adanya pengembangan M-Kamus Istilah Penelitian dalam Bahasa Arab berbasis Android. Dengan itu, peneliti menyimpulkan perlu adanya pengembangan M-Kamus tersebut. Manfaat dan kelebihan dari kamus digital M-Kamus istilah penelitian dalam bahasa Arab secara umum adalah memudahkan pengguna (user) untuk mencari istilah penelitian dalam bahasa Arab dengan cepat dan efisien, karena isi materi di dalam kamus hanya berisi tentang istilah yang berhubungan dengan penelitian saja. Pengguna (user) tinggal menulis istilah penelitian dalam bahasa Indonesia setelah itu pilih tombol cari maka secara otomatis akan muncul istilah penelitian dalam bahasa Arab.

Manfaat dan kelebihan yang lain dari M-Kamus istilah penelitian dalam bahasa Arab secara khusus adalah sangat memudahkan mahasiswa bahasa Arab mencari istilah penelitian dalam bahasa Arab dengan cepat. Bagi mahasiswa semester lima yang mengambil mata kuliah Manhaj Buhûus Ilmi, M-Kamus ini menjadi media penunjang belajar untuk mengenal lebih jelas tentang istilah-istilah penelitian dalam bahasa Arab, sedangkan bagi mahasiswa semester enam yang mengambil mata kuliah Nadwah Ilmiah, M-Kamus ini dibutuhkan untuk membantu mereka dalam menulis proposal penelitian menggunakan bahasa Arab, sedangkan bagi mahasiswa semester delapan, M-Kamus ini dibutuhkan bagi mereka yang sedang menempuh mata kuliah skripsi, karena skripsi mahasiswa PBA ditulis dengan dua bahasa, yaitu bahasa Indonesia dan bahasa Arab. 


\section{Metode Penelitian}

Penelitian ini menggunakan jenis penelitian kualitatif dan kuantitatif dengan desain penelitian dan pengembangan yang biasa disebut Research and Development. Metode $R \& D$ adalah metode penelitian yang digunakan untuk menghasilkan produk tertentu, dan menguji keefektifan produk tersebut (Sugiyono, 2011: 407). Pengumpulan data dalam penelitian ini dilakukan dengan menggunakan teknik non tes, yaitu wawancara, angket kebutuhan, angket uji validasi dan dokumentasi.

Subjek penelitian dalam penelitian ini adalah mahasiswa Pendidikan Bahasa Arab semester enam dan semester delapan di Universitas Negeri Semarang yang terdiri dari 11 mahasiswa semester enam dan 24 mahasiswa semester delapan. Peneliti mengambil 35 mahasiswa tersebut secara acak untuk dijadikan sampel dalam penelitian.

\section{Angket/Kuesioner}

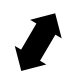

\section{Wawancara $\Leftrightarrow$ Dokumentasi}

\section{Bagan 1. Triangulasi Teknik}

Penelitian ini menggunakan triangulasi teknik dan sumber. Pengambilan data dilakukan dengan wawancara mahasiswa bahasa Arab berkaitan dengan kondisi pengetahuan mahasiswa bahasa Arab tentang istilah dalam penelitian bahasa Arab, bagaimana pemahaman mahasiswa bahasa Arab terhadap istilah penelitian bahasa Arab, bagaimana mahasiswa memanfaatkan media untuk mencari istilah penelitian dalam bahasa Arab. Kemudian metode dokumentasi digunakan untuk mencari datadata tambahan yaitu kamus khusus istilah penelitian bahasa Arab untuk menambahkan data dan istilah penelitian dalam bahasa Arab.

Selanjutnya data diperkuat melalui penyebaran angket kepada mahasiswa Pendidikan Bahasa Arab semester enam dan delapan terhadap penggunaan media untuk mencari istilah penelitian dalam bahasa Arab, kebutuhan mahasiswa bahasa Arab terhadap M-Kamus serta spesifikasi M-Kamus istilah penelitian dalam bahasa Arab yang akan dikembangkan untuk menghasilkan hasil data yang sama agar 
dinyatakan valid. Di samping angket kebutuhan, juga diperkuat dengan angket validasi yang ditunjukkan kepada dosen bahasa Arab di UNNES sebagai ahli materi, dosen pembimbing, dan ahli media terkait penilaian terhadap produk yang telah dibuat, sehingga pengembangan M-Kamus istilah penelitian dalam bahasa Arab benar-benar valid dan layak dijadikan sebagai media kamus elektronik bagi mahasiswa bahasa Arab untuk mencari istilah dalam penelitian bahasa Arab.

\section{Konsep Kamus Peneletian Bahasa Arab berbasis Android}

Kata kamus berasal dari bahasa Arab qâmûs yang dipinjam dari bahasa Yunani (okcamus) yang berarti lautan atau samudra. Melalui penyesuaian bunyi q menjadi k, kamus dapat berarti buku acuan yang memuat daftar kosakata sedemikian banyak yang disusun secara alfabetis atau dengan sesuai abjad berikut keterangan tentang makna, pemakaian, atau terjemahannya (Izzan, 2015: 190). Menurut Kamus Besar Bahasa Indonesia (KBBI: 614) definisi kamus adalah buku acuan yang memuat kata dan ungkapan, biasanya disusun menurut abjad berikut keterangan makna, pemakaian atau terjemahannya. Buku yang memuat kumpulan istilah atau nama yang disusun menurut abjad beserta penjelasan tentang makna dan pemakaiannya.

Simatupang (2000: 123) menyatakan ada berbagai jenis kamus berdasarkan bahasa dan topik. Kamus yang berdasarkan bahasa adalah kamus ekabahasa atau monolingual, yaitu arti kata diberikan dalam bahasa yang sama. Kamus dwibahasa atau bilingual, yaitu arti kata diberikan dalam bahasa lain. Ada juga kamus yang memiliki lebih dari dua bahasa yang berbeda, tetapi ini jarang.

Menurut Hakim dan Ferdian Rizka (Keswati 2014: 21) kamus ada tiga macam, yaitu: (1) Kamus Buku (mu'jam alkitab) adalah kamus yang khusus dibuat untuk memahami makna dari kosakata yang termuat dalam sebuah buku. (2) Kamus Digital adalah perangkat lunak komputer (software) yang memuat program terjemah atau kamus bahasa yang bisa dijalankan melalui media elektronik seperti computer, handphone, PDA, dan perangkat lainnya. (3) Kamus On-Line adalah kamus yang bisa diakses melalui internet. Para netter sering memanfaatkan jasa terjemahan kamus online pada browsing ke situs-situs di internet.

Setiap kamus pada umumnya memuat setidaknya tiga bagian, yaitu bagian depan, isi, dan pelengkap (Hermawan, 2011: 262). Dan menurut Keraf (2009: 46) sebuah 
kamus biasanya terdiri dari tiga bagian utama, yaitu Bagian Pendahuluan, Isi Kamus, dan Bagian Pelengkap. Menurut Chaef (Keswati 2015: 25) berpendapat bahwa selain berfungsi sebagai wadah penghimpun konsep-konsep budaya, kamus juga memiliki fungsi-fungsi praktis. Seperti sarana untuk mengetahui makna kata, sarana mengetahui lafal dan ejaan sebuah kata, sarana untuk mengetahui asal-usul kata, dan sarana untuk mengetahui berbagai informasi mengenai kata lainnya.

Kamus sangatlah penting dalam menerjemahkan teks bahasa asing, apalagi bagi pemula. Kamus ibarat kotak yang berisikan mutiara yang selalu diburu, atau bak ibu bagi anak yang masih menyusu. Dari pandangan itu, kemahiran menggunakan kamus sangat berperan dalam penerjemahan (Huda 2012: 152). Menurut Keraf (2009: 69) kamus memegang peranan yang sangat penting. Bila kita berjumpa dengan sebuah kata baru, atau sebuah kata lama dalam sebuah konteks baru, maka kamus sudah siap untuk membenarkan dugaan kata tersebut. Kamus menyuguguhkan sebuah daftar kata, masing-masing dengan batasan pengertian yang sedang berlaku atau yang tidak berlaku.

Penelitian merupakan padanan dari kata al-bahtsu al-'ilmiy yang berarti mencari sesuatu, menyelidiki, dan memeriksa (Sulaiman dalam Ainin 2010: 8). Menurut istilah Penelitian adalah proses pengumpulan dan analisis data yang dilakukan secara sistematis dan logis untuk mencapai tujuan tertentu (Sukmadinata 2012: 5). Menurut Abu Ali (2013: 9) penelitian adalah mencari pengetahuan seputar tema tertentu, dan menggunakan secara lengkap dengan media dan instrumen yang tersedia untuk mengungkapkan pengetahuan tersebut.

Jenis-jenis metode penelitian dapat diklafisikasikan berdasarkan tujuan dan tingkat kealamiahan (natural setting) obyek yang diteliti. Berdasarkan tujuan, metode penelitian dapat diklasifikasikan menjadi penelitian dasar (basic research), penelitian terapan (applied research) dan penelitian pengembangan (research and development). Selanjutnya berdasarkan tingkat kealamiahan, metode penelitian dapat dikelompokkan menjadi metode penelitian eksperimen, survey dan naturalistik (Sugiyono, 2014: 4).

Android adalah sebuah sistem operasi yang berjalan pada perangkat mobile berbasis linux yang mencakup sistem operasi, middleware, dan aplikasi. Android menyediakan platform terbuka bagi para pengembang untuk menciptakan aplikasi mereka. Awalnya, Android dikembangkan oleh Android, Inc. dengan dukungan finansial dari Google Inc., yang kemudian membeli Android Inc. yang merupakan pendatang baru 
yang membuat peranti lunak untuk ponsel/smartphone pada tahun 2005. Kemudian untuk mengembangkan Android, dibentuklah Open Handset Alliance, konsorium dari 34 perusahaan peranti keras, peranti lunak, dan telekomunikasi, termasuk Google, HTC, Intel, Motorola, Qualcomm, T-Mobile, dan Nvidia. Sistem operasi ini resmi dirilis pada tahun 2007 dan ponsel Android pertama mulai dijual pada bulan Oktober 2008. (Yudhanto \& Wijayanto, 2017: 1)

Pada saat ini, penggunaan sistem aplikasi Android tidak hanya pada perangkat mobile saja, tetapi berkembang pada tablet PC, Smart TV, Smart Car, dan perangkat lainnya. Pesatnya pertumbuhan Android selain faktor yang disebutkan di atas adalah karena Android itu sendiri adalah platform yang sangat lengkap baik itu sistem operasinya, aplikasi dan tool pengembangannya, pasar aplikasi Android serta dukungan yang sangat tinggi dari komunitas Open Source di dunia, sehingga Android terus berkembang pesat baik dari segi teknologi maupun dari segi jumlah device yang ada di dunia (Safaat H, 2013: 2). Dan pengembangan M-Kamus Istilah Penelitian dalam Bahasa Arab berbasis Android karena kemudahan dalam pemakaiannya dan pengembangan lebih lanjut, serta mudahnya diakses oleh banyak orang karena kepemelikan perangkat berbasis Android sangatlah banyak.

\section{Pengembangan M-Kamus Istilah Penelitian dalam Bahasa Arab bagi Mahasiswa Pendidikan Bahasa Arab Universitas Negeri Semarang}

Berdasarkan hasil penelitian, M-Kamus istilah penelitian dalam bahasa Arab berbasis Android menjadi aplikasi yang diperlukan untuk mencari istilah penelitian dalam bahasa Arab dengan mudah dan cepat. M-Kamus istilah penelitian dalam bahasa Arab akan mempunyai fitur-fitur, seperti pencarian kata, profil, riwayat pencarian, dan petunjuk penggunaan di dalamnya. Penggunaan jenis huruf latin akan menggunakan Times New Roman dengan ukuran 14 dan untuk jenis huruf Arab akan menggunakan Traditional Arabic dengan harakat dan ukuran huruf 18. Susunan kata di dalam MKamus istilah penelitian akan disusun berdasarkan abjad. Dan bahasa yang digunakan adalah bahasa Arab dan bahasa Indonesia. 
Adapun prototype awal M-Kamus Istilah Penelitian adalah sebagai berikut:

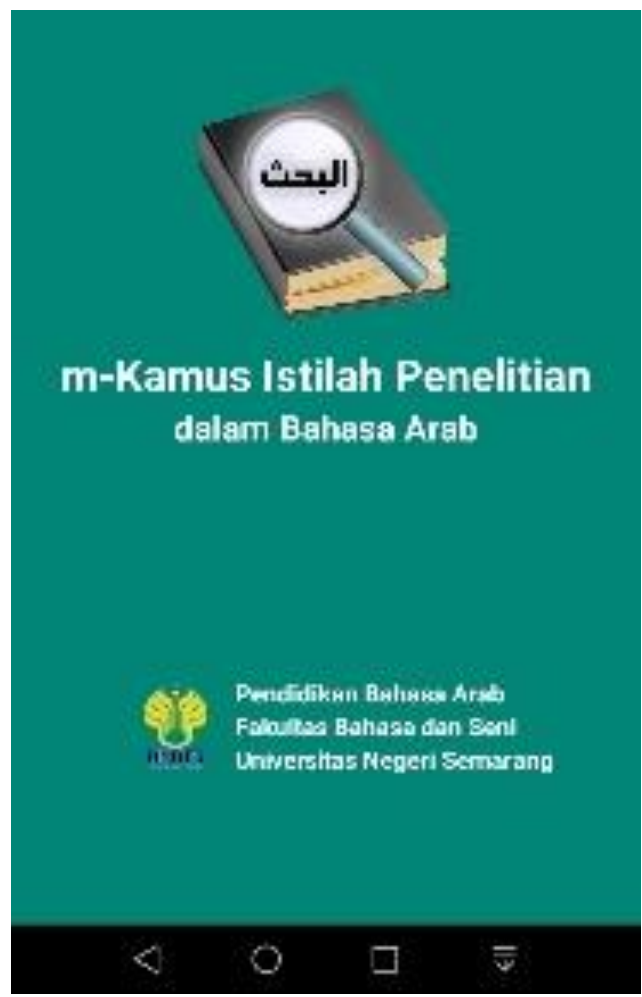

Gambar 1. Halaman Utama M-Kamus Sebelum Revisi

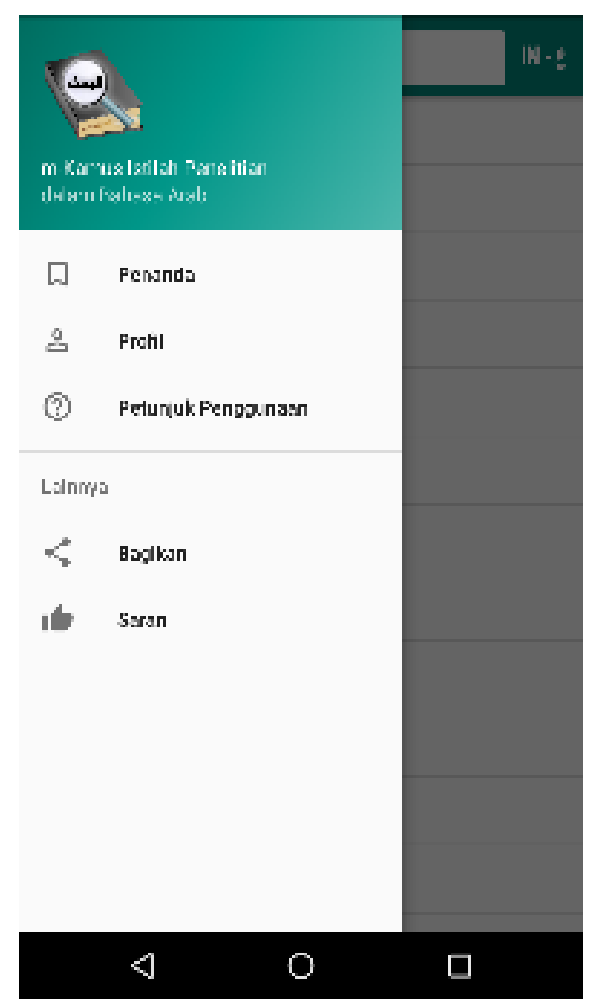

Gambar 2. Halaman Depan M-Kamus Sebelum Revisi 
Hasil analisis penilaian ahli media dan materi terhadap prototipe M-Kamus Istilah Penelitian dalam Bahasa Arab adalah sudah sangat layak atau sangat sesuai, dengan beberapa masukan dan saran untuk menjadikan M-Kamus lebih baik. Adapun saran dan masukan yang diberikan adalah (1) Pengkoreksian pemberian harakat atau tanda baca dengan lebih teliti, (2) Perbaikan pada beberapa istilah bahasa Indonesia, (3) Lebih teliti dalam pemindahan deskripsi dan makna istilah dari sumber referensi. (4) Penambahan navigasi home agar lebih mudah untuk kembali ke halaman isi. (5) Pengubahan menu bagikan menjadi menu info tentang M-Kamus sehingga pengguna mengetahui informasi tentang M-Kamus Istilah Penelitian dalam Bahasa Arab. (5) Penambahan penjelasan pada kosakata yang ada. (6) Pengubahan gambar latar belakang halaman utama agar lebih menarik.

Beberapa perbaikan yang peneliti lakukan berdasarkan masukan dan saran dari para ahli media dan materi, sebagai berikut:

Sebelum

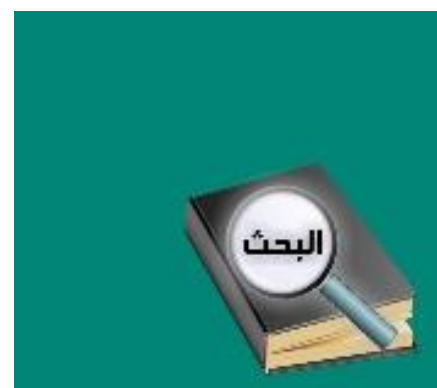

m-Kamus Istilah Penelitian dalam Bahasa Arab

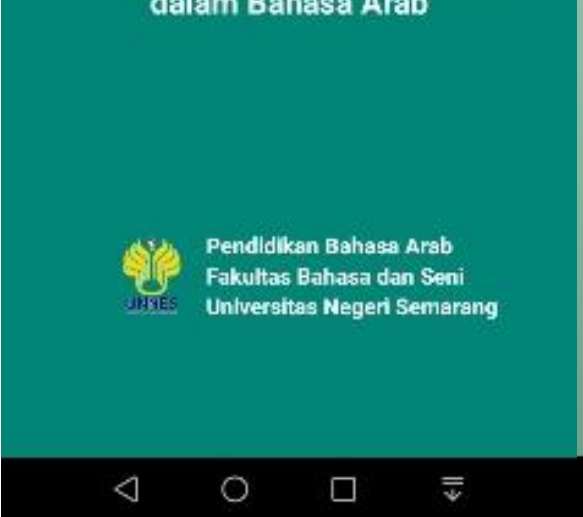

Gambar 3. Perbaikan pada Halaman Utama M-Kamus

\section{Sesudah}

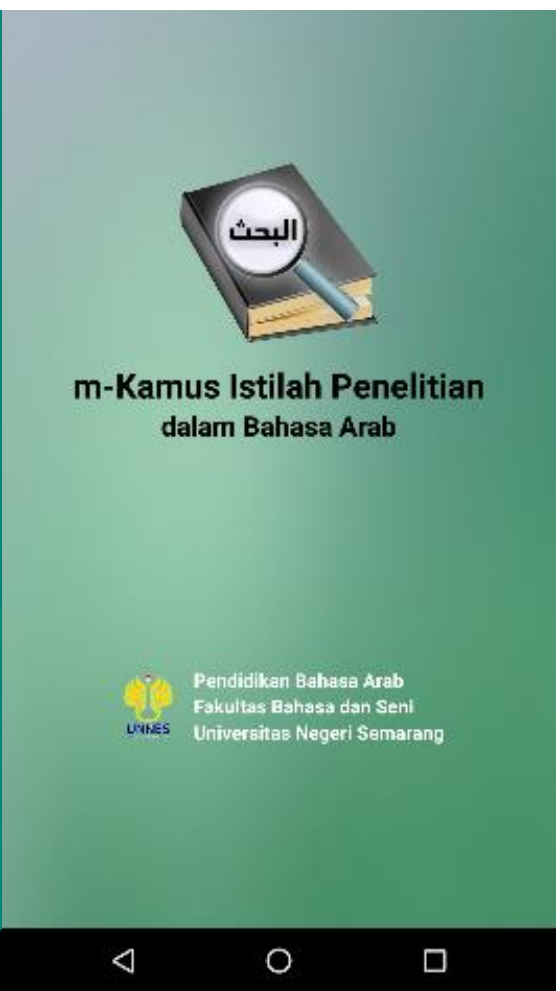


Pebaikan pada halaman utama M-Kamus agar tampilan menjadi lebih menarik.

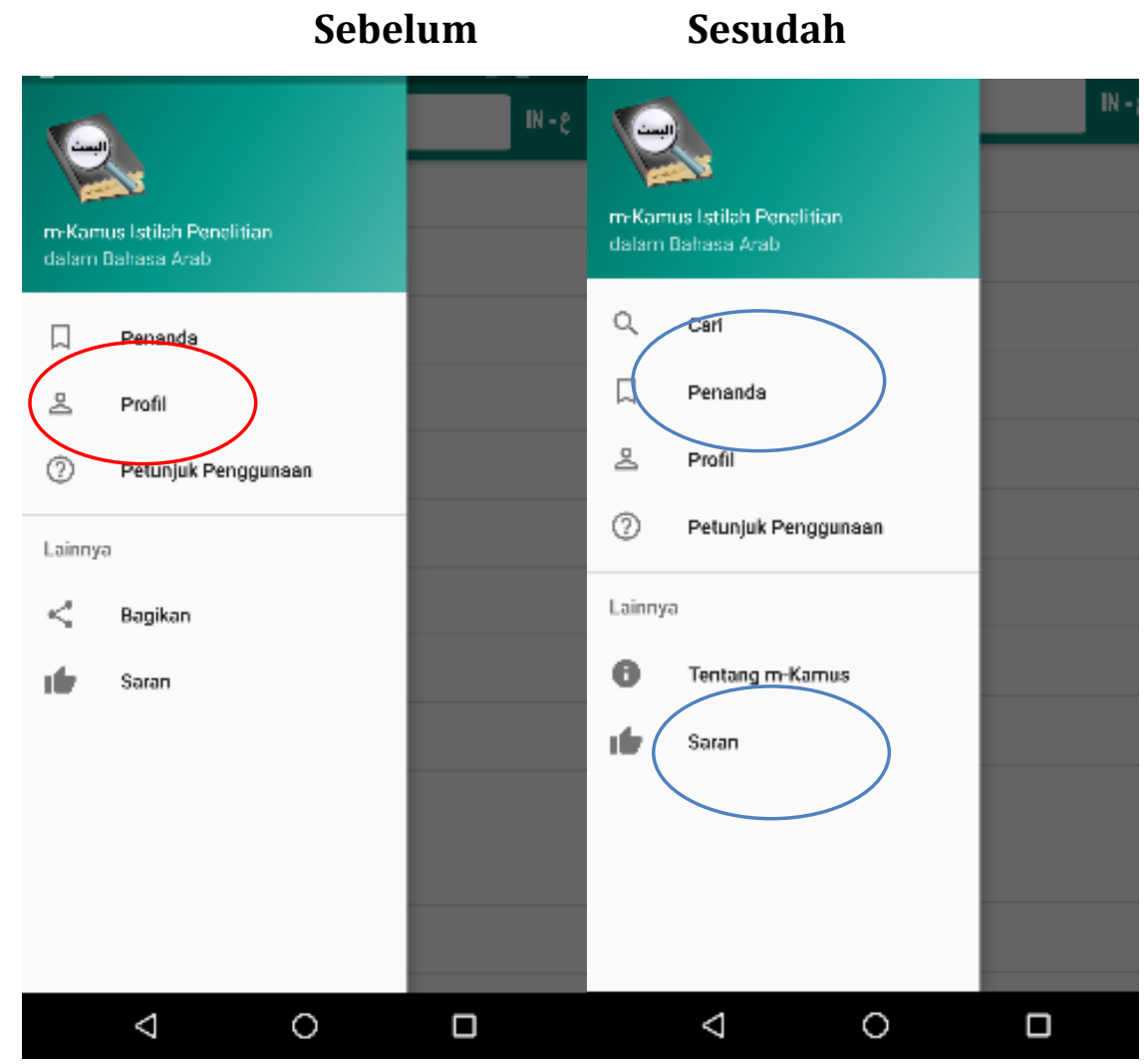

Gambar 4. Perbaikan pada Halaman Depan M-Kamus

Perbaikan pada halaman depan M-Kamus adalah penambaha menu Cari dan pengubahan menu Bagikan menjadi Tentang M-Kamus.

Berikut adalah hasil rekapitulasi dari total nilai yang didapatkan dari penilaian para ahli :

Tabel 1. Total Nilai yang Didapatkan

\begin{tabular}{cll}
\hline No. & Aspek Penilaian & Nilai \\
\hline 1 & Aspek rekayasa perangkat lunak & 86,5 \\
\hline 2 & Aspek komunikasi & 84,1 \\
\hline 3 & Aspek visual & 85,8 \\
\hline 4 & Aspek kelayakan isi & 86,8 \\
\hline 5 & Aspek kelayakan penyajian & 88,1 \\
\hline 6 & Aspek kelayakan bahasa & 88,1 \\
\hline & Total & 86,57
\end{tabular}

Berdasarkan tabel 1 di atas, dapat disimpulkan bahwa M-Kamus Istilah Penelitian dalam Bahasa Arab dinyatakan sangat layak untuk digunakan dengan total nilai $86,57$. 


\section{Kesimpulan}

Berdasarkan hasil penelitian dan pengembangan (R\&D) berjudul M-Kamus Istilah Penelitian dalam Bahasa Arab berbasis Android bagi Mahasiswa Pendidikan Bahasa Arab di Universitas Negeri Semarang, dapat dikemukakan kesimpulan bahwa:

Hasil analisis kebutuhan mahasiswa terhadap M-Kamus Istilah Penelitian dalam Bahasa Arab menunjukkan bahwa mahasiswa menghendaki aplikasi M-Kamus yang berisi 6 komponen utama, yaitu Cari, Penanda, Profil, Petunjuk Penggunaan, Tentang MKamus, dan Saran. Sedangkan Prototipe M-Kamus Istilah Penelitian dalam Bahasa Arab berupa aplikasi yang dapat dijalankan menggunakan semua jenis smartphone berbasis Android tanpa menggunakan koneksi internet yang berisi kurang lebih 400 istilah penelitian dalam bahasa Indonesia dan bahasa Arab. Aplikasi M-Kamus Istilah Penelitian dalam Bahasa Arab berbasis Android ini dibangun dengan menggunakan program Android Studio. Dan desain ikon, dan layout dengan menggunakan program Corel Draw X7 dan Adobe Photoshop CS3.

Analisis penilaian ahli dan stakeholder terhadap desain dan materi aplikasi MKamus Istilah Penelitian dalam Bahasa Arab dapat ditarik kesimpulan bahwa aplikasi ini sangat sesuai dan baik dalam aspek rekayasa perangkat lunak, komunikasi, visual, kelayakan isi, kelayakan penyajian, dan kelayakan bahasa dengan total nilai . Saran dan masukan dari para ahli dan stakeholder meliputi: 1) ketelitian dalam penulisan istilah bahasa Arab maupun bahasa Indonesia dan penukilan pengertian istilah penelitian dari sumbernya, 2) perbaikan pada tampilan awal aplikasi agar lebih menarik, 3) penambahan dan pengubahan beberapa fitur dalam M-Kamus.

\section{Daftar Rujukan}

Abu Ali, Nabil Kholid. Al-Bahtsu Al-Adabiy wal Lughowiy (Thobi'atuhu-ManahijuhuIjroaatuhu). Beirut : Dar Al-Kutub Al-'Ilmiyah, 2012.

Ainin, M. Metodologi Penelitian Bahasa Arab. Surabaya: Hilal Pustaka, 2010.

Ainin, M. Metodologi Penelitian Peningkatan Kualitas Pembelajaran Bahasa Arab. Malang: Bintang Sejahtera, 2014.

Arikunto, Suharsimi. Prosedur Penelitian Suatu Pendekatan Praktek. Jakarta: Bumi Aksara, 2005.

Emzir, M. Metodologi Penelitian Kualitatif Analisis Data. Jakarta: Rajawali Pers, 2011. 
Hakim, Ahmad Lukman dan Ferdian Rizka. Sistematika Penyusunan Kamus Berdasarkan Entri, Jumlah Bahasa, dan Masa/Periode. Makalah disajikan untuk memenuhi tugas Mata Kuliah Leksikologi, Leksikografi Bahasa Arab. Yogyakarta: Universitas Ahmad Dahlan, 2013.

Hamidi. Metodologi Penelitian Kualitatif. Malang: UMM Press, 2000.

Hermawan, Acep. Metodologi Pembelajaran Bahasa Arab. Bandung: Rosdakarya, 2013.

Huda, Nurul. Tocker Bahasa Arab. Yogyakarta: Bening, 2012.

Izzan, Ahmad. Metodologi Pembelajaran Arab. Bandung: Humaniora, 2015.

KBBI, Tim Penyusun. Kamus Besar Bahasa Indonesia. Jakarta: Balai Pustaka, 2002.

Keraf, Gorys. Diksi dan Gaya Bahasa. Jakarta: PT Gramedia Pustaka Utama, 2009.

Keswati. Pengembangan Kamus Bahasa Arab untuk Buku Ta'lim Al-Lughoh Al-'Arobiyah sebagai Penunjang Buku Bahasa Arab Kelas VIII Madrasah Tsanawiyah. Skripsi: Universitas Negeri Semarang, 2014.

Kristianto, Aditya Wahyu. Pengembangan Media Pembelajaran E-Kamus Komputer Teknologi Informasi dan Komunikasi Menggunakan Microsoft Visual Basic 6.0 Kelas VII SMP Negeri 1 Welahan. Skripsi: Universitas Negeri Semarang, 2013.

Moelung. Metodologi Penelitian Kualitatif. Bandung: PT Remaja Rosdakarya, 2010.

Mu'minin, Imam Saiful. Kamus Ilmu Nahwu dan Shorof. Jakarta: Amzah, 2013.

Narbuko, Cholid, dan Abu Achmadi. Metodologi Penelitian. Jakarta: Bumi Aksara, 2013.

Peraturan Menteri Riset, Teknologi, dan Pendidikan Tinggi Republik Indonesia No .16 Tahun 2015.

Rochman, Rijal Nur. E-Kamus Istilah Penelitian dalam Bahasa Arab Menggunakan Microsoft Visual Studio 2010 bagi Mahasiswa Pendidikan Bahasa Arab di Universitas Negeri Semarang. Skripsi: Universitas Negeri Semarang, 2016.

Safaat H, Nazruddin. Android: Pemrograman Aplikasi Mobile Smartphone dan Tablet PC Berbasis Android. Bandung: Informatika, 2013.

Sanjaya, Wina. Penelitian Pendidikan Jenis, Metode dan Prosedur. Jakarta: Kencana Prenada Media Group, 2013.

Setiyadi, Bambang. Metodologi Penelitian untuk Pengajaran Bahasa Asing. Yogyakarta: Graha Ilmu, 2006.

Simatupang, Maurits D.S. Pengantar Teori Terjemahan I. Direktorat Jenderal Perguruan Tinggi, 1999/2000.

Siregar, Shofyan. Statistik Deskriptif untuk Penelitian. Jakarta: Rajagrafindo Persada, 2010. 
Sugiyono. Metode Penelitian Kombinasi (Mixed Methods). Bandung: Alfabeta, 2011.

Sugiyono. Metode Penelitian Pendidikan Pendekatan Kuantitatif, kualitatif, dan R\&D. Bandung: Alfabeta, 2014.

Sugiyono. Metodologi Penelitian Pendidikan. Bandung: Alfabeta, 2013.

Sukmadinata, Nana Syaodih. Metode Penelitian Pendidikan. Bandung: Remaja Rosdakarya, 2012.

Tarigan, Henry Guntur. Pengajaran Semantik. Bandung: Angkasa, 2009.

Unnes, FBS. Pedoman Penulisan Skripsi. FBS: UNNES, 2014.

Yudhanto, Yudha, dan Ardhi Wijayanto. Mudah Membuat dan Berbisnis Aplikasi Android dengan Android Studio. Jakarta: PT. Elex Media Komputindo, 2017. 